\title{
Are All Adult Stem Cells The Same?
}

\author{
Arnold I. Caplan, PhD ${ }^{1}$
}

Received: 9 April 2015 / Accepted: 3 July 2015 /Published online: 1 September 2015

(C) The Regenerative Engineering Society 2015

\begin{abstract}
Every adult tissue has its own resident committed progenitor or stem cell. In addition, there exists a class of adult stem cells that are multipotent and/or have injury-specific functions. Mesenchymal stem cells (MSCs) are quite different in comparison with neural stem cells (NSCs) when focusing on the range of different differentiated cell types that can develop from their progeny. These striking differences aside, MSCs, NSCs, and hematopoietic stem cells (HSC) have a very striking number of similarities. They are all dominant cells, multipotent, have a well-defined niche on or in contact with blood vessels, they all actively sense and respond to their local environment, they are all paracrine secretors, they are all immune-modulatory and trophic, and they all have a profound effect on site-specific regeneration following injury. These similarities, especially their unique interactions and association with vasculature, distinguish these adult cells from their embryonic progenitors and by virtue of these similarities define these unique adult stem cells.
\end{abstract}

\section{Lay Summary}

The adult body has many stem cells, at least one for every major tissue. These stem cells provide the basis for the maintenance, repair, and regeneration of these tissues. These stem cells can divide and differentiate into a specialized tissue like muscle or liver. However, stem cells from different tissues have a common core of properties that are similar in function. For example, the hematopoietic stem cell (HSC) produces all the cells in blood. The mesenchymal stem cell (MSC) can

Arnold I. Caplan, PhD

arnold.caplan@case.edu

1 Skeletal Research Center, Department of Biology, Case Western Reserve University, Cleveland, OH 44106, USA produce fat or bone. The HSC and MSC function at tissue sites of injury to cause the tissue to regenerate. Thus, the HSC and MSC do the same injury function although they are uniquely different. Moreover, each stem cell establishes a unique habitat next to or in contact with blood vessels.

Keywords Neural stem cell (NSC) $\cdot$ Mesenchymal stem cell (MSC) · Hematopoietic stem cell (HSC) · Vasculature ·

Regeneration

\section{Introduction}

There are now a large number of human stem cells that are being studied and reported in both the scientific and lay literature. Clearly, the array of stem cells and their differences seem almost too complicated to grasp which may require simplifying groupings or new logics. This is even more complicated because there are both an array of tissue progenitors at various progressive stages of embryonic development and tissue-specific adult stem cells, which do different things and contribute to the changing biology of the organism in intricately different ways. Below, the focus of this treatise is only on adult human stem cells and their embryonic forefathers are left to others to discuss. The important distinction of this focus is the long and interesting list of cellular features that all adult stem cells have in common, not on the complex spectrum of distinctive phenotypes that the stem cells can become. The unexpected and simplifying conclusion is that all adult stem cells have a similar profound paracrine activity that is essential for the normal turnover and regeneration especially active and discernable at sites of injury [1-6]. 


\section{Adult Stem Cells}

There are many adult stem cells, perhaps one or more for each tissue of the body. For the sake of brevity, the focus will be on the few that have been extensively studied. This is not to say that the liver stem cell $[7,8]$, the heart stem cell $[9,10]$, and the skeletal muscle stem cell $[11,12]$ which are not described here have not been studied or do not represent important examples to be seriously considered. The provocative use of the word ALL in the title and elsewhere is to suggest that all of these adult stem cells likewise fit in the simplifying, common categories considered herein.

HSCs The longest studied and most clinically relevant adult stem cell is the hematopoietic stem cell (HSC) and, indeed, until the earlier 1990s, it was reported to be the only stem cell that still functioned in the adult [13-15]. The focus of most studies on all stem cells is to trace where they reside and then where and into what they will differentiate. In the case of the HSCs, this not only involves tracing the lineage pathways for the 20-30 unique and individual blood cell types derived from the parental HSC but also the identification of the bioactive factors that control each step of the lineage differentiation process $[16,17]$. Indeed, the biotechnology and pharmaceutical companies have used these basic lineage pathways and effector identification information to test and bring to market powerful drugs that can control the HSC differentiation to produce specific blood cells [18]. For example, erythropoietin (EPO) has long been on the market to control and accelerate the formation of red blood cells from HSCs. In this regard, the lay press has recently focused on the illegal use of EPO in competitive cycling and other sport activities emphasizing what the pharmaceutical management of HSCs can produce and their beneficial effects on human performance and physiology [19, 20]. Importantly, if all HSCs are extinguished in the body as can happen with some chemotherapy protocols, new blood cells will not arise to replenish those that naturally expire causing a lifethreatening situation. In this case, HSCs must be provided from exogenous sources commonly referred to as bone marrow transplantation. Clearly, the adult HSC is absolutely necessary for life, because its descendants perform a complex array of life sustaining activities and tasks.

In this context, the re-establishment of the adult HSC niche following ablative chemotherapy and bone marrow or hematopoietic progenitor transplant does not simply involve reengraftment in the repairing marrow. The HSC and early progenitors home to the spleen and liver and set up colonies of multiplying cells. Eventually, there is a migration of some of these cells back to the bone marrow. The sequence and timing of re-engraftment and the re-establishment of the HSC niche with the identification of the controlling elements are yet to be described [21-26].

NSCs The same very complex set of differentiation and life-giving descendants can be established for almost all of the other adult stem cells. For example, the neurostem cells (NSCs) can differentiate into an amazing array of neurons and neural-support cells such as oligodendrocytes and astrocytes [27, 28]. Again, the central theme of such studies is to determine what bioactive factors control each step in the complex, multi-legged differentiation lineage pathways and the gain of function resulting from these differentiated descendants of NSCs when they come on-line in the nervous system. In this case, the intrinsic NSCs are available to replenish neurons which expire or to produce new neurons for gainof-function situation. In addition, the NSCs give rise to neural-support cells that turnover or to oligodendrocytes that wrap axons with myelin. Importantly, if NSCs could be stimulated to form functional oligodendrocytes for neurons denuded of myelin (as is the case, in MS), function could be restored in the newly myelinated axons $[27,29,30]$.

Again, in this case, the NSCs are found in intimate association with blood vessels [31-33]. In addition, there are NSC niches in different sectors of the brain and elsewhere in the nervous system. The prediction that although these wide-spread NSCs will have many features in common, their chemistry and default differentiation pathway could be expected to be different since their niches have different microchemistries.

MSCs The multipotent mesenchymal stem cells (MSCs) have been studied since the 1970s [34], and purified preparations were first commercialized as a reagent for research and development in the 1990s [35]. The proposal was that, like the HSCs found in bone marrow, the MSCs found in marrow could be separately induced into several mesenchymal lineage differentiation pathways to form bone, cartilage, muscle, fat, bone marrow stroma, etc. The marrow MSCs were shown to be capable of such differentiation in vitro into the complete spectrum of mesenchymal phenotypes and in the case of bone, also in vivo studies directly traced the MSCs into cells that fabricate bone [34-38].

That said, in the mid-1990s, it was recognized that marrow MSCs in culture could strongly inhibit the classical mixed lymphocyte reaction (MLR) and, thus, were immune-modulatory. Since these initial findings, MSCs have been shown to secreted bioactive factors that have been shown to affect almost all of immune systems' cells and functions when assayed in the proper context $[39,40]$. The original claims were that 
allogeneic MSCs were so powerfully regulatory that they could be "universally" (i.e., allogenically) used without immunosuppression in all cell therapy applications [39-42]. This claim turns out to be mostly correct but for reasons quite different from originally envisioned. In this regard, MSCs are not immune-privileged but are rather immune-evasive [43]; this evasive function can have profound therapeutic implications including tuning down the host's immune system when used as chaperons for organ transplantation [44] or when supplied to patients with graft-versus-host disease [45].

One other capacity of MSCs that is important to delineate is their trophic capacity. In studies of NSCs [46], Miller and his colleagues used human marrow-derived, MSCs conditioned medium and found that it had a profound effect on the differentiation of NSCs in culture. The MSCs 3-day growth medium was able to affect in vitro NSC differentiation by decreasing the number of glial cells that formed by a factor of 10 and increasing the number of oligodendrocytes that formed by a factor of four [27, 32]. These startling observations lead Miller and colleagues to test human MSCs in the mouse EAE model for MS [47]. A single dose of MSCs in the tail vein halted the destructive immunologic activity and completely cured the mouse of all symptoms of MS. When the central nervous system was studied histologically, it was clear that hostderived oligodendrocytes had formed and were rewrapping the axons previously denuded by the immune system.

In the same time-frame as the studies above, the trophic activities of MSCs [48] were established by a number of independent laboratories. In summary of these studies, MSCs produced molecules that (A) inhibited scar formation, (B) inhibited ischemia-caused apoptosis, (C) stimulated tissue-specific stem cell mitosis, and (D) stimulated rapid revascularization of injury sites [48-50]. These diverse capabilities have been summarily referred to as trophic activities which can be seen in the regenerative repair of injury sites in vivo. All of the adult stem cells [51] exhibit this paracrine trophic capacity in different manners at different sites and to different extents but usually containing these four activities.

Pericytes Last, MSCs have been traced to originate from perivascular mesenchymal cells (pericytes) $[52,53]$; these abluminal cells are embedded in the basement membrane of blood vessels. Experimental observations clearly document that both endogenous and exogenously supplied MSCs have the capacities to immune-modulate and protect injury sites from immune-destructive events and to provide a trophic microenvironment for the regeneration (not repair) of the injured tissue. These MSCs go to sites of vascular discontinuity or inflammation which is where released pericytes naturally function $[24,54]$. The immune-modulatory and trophic functions are dominant and precede any differentiation of these MSCs. These observations stimulated the proposal of a new name for medicinal signaling cells (MSC) since none of these paracrine regenerative activities are related to the multipotentiality of the cells (i.e., not true "stem" cells under these conditions) [55].

\section{All Adult Stem Cells}

Rather than focus on all of the separate and quite different differentiation lineage pathways of each of the uniquely different adult stem cells, it is quite striking to consider all of the activities that all adult stem cells have in common. For the sake of brevity, I abbreviate human adult stem cells (haSCs):

Mitotic All haSCs are mitotic and, in principle, at least one daughter cell remains as a stem cell [56].

Multipotent All haSCs are multipotent; in cell culture challenges with specific inductive factors, multiple phenotypes can be recognized to form [57-61].

Niche All haSCs are found in highly structured multicellular clusters in contact with blood vessels. This localization at vascular sites is quite striking and emphasizes the inter-dependence of haSCs and vascular components $[21-23,62-65]$. The dependence of haSCs on their niches is in counter distinction to embryonic stem cells (ESCs) that are not niche dependent. For all of these haSCs, the niche is in intimate contact or association with vasculature (with endothelial cells) and is a special place where the stem cell can be quiescent but hooked in to the physiology of the tissue and, indeed, the entire organism through the circulating blood stream. Both the cells in the immediate vicinity and the vascular endothelial cells provide the local physiologic response team, the elements that impart a tissue or functional identity to the SC [31-33, 63]. For example, the HSC niche involves a cluster of cells that secrete informational molecules including nestin-positive MSCs/osteoblasts that can be, likewise, activated by injury or inflammation. Thus, the niche for haSCs is a special sanctuary physically and functionally connected to the whole organism. Its unique chemistry can provide the haSCs with "memory" by each location imparting an identity to the haSC. This niche dependence and imprinting is why iPs-MSCs [58, 59] are probably not functionally identical to native haSCs.

Dominant All haSCs are paracrine dominant in their in vivo activities. In clusters of diverse cells in tissues or at sites of injury, their secretory products control or are commanding in the tissue field compared to the other cells $[65,66]$. 
Responsively Sensory All haSCs are exquisitely sensitive to the composite microenvironment in which they engraft or reside. Importantly, in injury microenvironments or implantations, the haSCs first deal with "fixing" the injury BEFORE responding to the differentiation needs of the site or organism [66-69]. This "sensory" activity is responsive to the dynamically changing microenvironment of an injury or regenerative site since an injury site clearly goes through substantial changes from its initiation to the final regenerative resolution. Yet to be determined is the issue of when, where, and how long do these powerful paracrine haSCs need to function at injury or regenerative sites. Indeed, the question can be asked: who makes the therapeutic molecules, the cells of injured tissue or haSCs? I would speculate in this regard that the haSCs help to stimulate and to manage the host tissues' intrinsic regenerative capabilities and that such localized regeneration must be site and tissue specific (i.e., stimulated by the haSC and controlled by the local components.).

Immuno-Modulatory All haSCs secrete molecules that essentially provide a barrier or curtain to inhibit all of the interrogators of the immune system from entering an injury or developmental tissue field $[69,70]$. This is not to say that the haSCs are not eventually rejected [71]. This curtain or modulatory activity is the first line of defense against the establishment of autoimmune conditions. This immune-modulatory capacity is clearly functioning in MSC treatment of graft-versus-host disease [45], organ transplantation [2, 44, 54], and animal models of MS [47] or asthma [54, 55].

Trophic All haSCs secrete bioactive factors that structure both physically and molecularly the injury or developmental (regenerative) field. This activity is not unique to neural element from which the term "trophic" is derived with regard to its biologic meaning (Greek meaning "feeding"). The secreted factors from motor neurons to the muscles they innervation which sustain or maintain the muscle units are referred to as trophic. Rather trophic for haSCs means contributing to a progressive and dynamically changing microenvironment that [48] supports regenerative activities (not the maintenance of the innervated muscle).

Paracrine Secretor All haSCs have a powerful and dynamically sustained secretory capability that accounts from all or most of the prominent activities listed above $[54,55]$. This secretory activity precedes any differentiation activity in the sense that the microenvironment must be managed to decrease the immune-intrusion and establish a regenerative milieu. Without such site preparation, the haSCs cannot differentiate should that site require differentiated descendants of the haSCs. The emphasis here is to highlight both the high quantity and spectrum of bioactive agents secreted by these cells especially at sites of injury. These cells in culture, likewise, exhibit high secretory activity [67-72].

Regenerative All haSCs provide regenerative microenvironments and under the appropriate conditions; the end result may be the initiation of their intrinsic differentiation cascade. At sites of injury, the quick-fix is the formation of scar tissue since the regeneration of the tissue is a much slower process requiring anatomic integration of the newly regenerative tissue [73, 74]. This slower dynamic process of tissue regeneration requires that several "quick-fix" modalities be inhibited and the slower formative processes enhanced.

Hard-Wired All haSCs have the immune-modulatory and trophic activities in vivo that survive experimentalists' attempts to culture expand these cells using complex media that is lab or company specific $[72,75,76]$. Long after the haSCs have lost their capacity to differentiate in vitro, the in vivo regenerative paracrine activities seem to survive these manipulation when the expended cells are implanted or exogenously supplied to injured tissue [77].

Homing All haSCs appear to "home" to sites of tissue injury, damage, or inflammation [24, 78]. The mechanism for this activity has yet to be delineated, but since the initiation of regenerative process involves the disruption of the haSC niche, it may be that such disruption releases or uncovers docking antigens that assist in the localization of the haSCs. The vascular endothelial cells may play a prominent role in attracting these regenerative cells to the injury site [31, 79].

\section{Who Secretes the Therapeutic Factors?}

The question needs to be asked: do the endogenous or exogenously supplied haSCs secrete the therapeutic molecules or do the host cells sitting near the haSCs secrete the key therapeutic bioactive molecules. The suggestion could be made that the paracrine activity of haSCs is stimulatory causing the host to secrete therapeutic factors which feedback on these responsive cells to provide host-driven regeneration. This logic further suggests that the haSCs help stimulate the tissue's natural and intrinsic capacities to regenerate themselves. Taken to an extreme, there are reports that a preparation of bladder extracellular matrix (ECM) can stimulate the reformation of severed fingers [80]. This implies that the bioactive factors 
in this ECM preparation cause the host to secrete factors that control the morphology of the composite tissues of the regenerated digits. Certainly, the regeneration of a severed digit cannot occur without the presence of additional control elements. Clearly, the host tissue must have or make these morphogenic bioactive molecules as an intrinsic capability that can be uncovered by the ECM factors. Can an entire arm or leg be regenerated? This is the challenge: to extend the reactions which successfully provided the stimulus for digit regeneration to reform entire appendages. This is both the goal of and dream of regenerative medicine.

Disclaimer Obviously, all haSCs are quite different in their cell-surface molecules, their innate chemistries, their embryonic origins, and functional capacities. Having stated the obvious, this short thesis focuses on some of the (also) very obvious similarities of these essential adult stem cells. The differences between a muscle progenitor cells (satellite cells) from fast and slow muscles $[81,82]$ are profound, thus, emphasizing that a spectrum of different properties should be expected even for adult muscle stem cells. Yet, these satellite cells have a huge number of responses and functional similarities. One of the most obvious but least emphasized characteristic of adult stem cells is that their niches are all intimately associated with blood vessels. This positioning connects them with the changing physiology of their home tissue and the entire organism. Thus, the response to injury, trauma, or cyclic changes ideally positions the stem cells to respond or remain quiescent. Perhaps, this relationship with the vasculature and the unique properties of the adult stem cell niche is the most important feature common to all adult stem cells.

The similarities, in the broadest sense, have been under-studied. With the availability of Panomics, the challenge will be to focus on BOTH the unique differences between haSCs and the profound similarities (which often are discarded or minimally identified). This treatise is provided as a provocative challenge to the regenerative medicine community to further identify the full spectrum of the complex capacities of haSCs. The research surrounding the medicinal properties of MSCs and their use in over 500 clinical trials (clinicaltrials.gov) with an amazing array of clinical maladies stimulated the logic to look for the common features of all haSCs.

\section{Future Directions}

Although implied in several instances above that cultureexpanded cells will be used clinically in the future, the tuning of these therapeutic cells to be optimal for both the tissue site and the genetics of the recipient has yet to be addressed. In this light, the management of the body's own haSC and the intrinsic developmental potential of each organ or tissue is also a formidable therapeutic frontier. Both exogenous and intrinsic haSC management will be required to cure a variety of complex diseases.

Acknowledgments I would like to thank the L. David and E. Virginia Baldwin Fund and NIH for their generous support.

\section{References}

1. Ruiz EJ, Oeztuerk-Winder F, Ventura J-J. A paracrine network regulates the cross-talk between human lung stem cells and the stroma. Nat Commun. 2013;5:3175.

2. Anthony DF, Shiels PG. Exploiting paracrine mechanisms of tissue regeneration to repair damaged organs. Transplant Res. 2013;2:10.

3. Burchfield JS, Dimmeler S. Role of paracrine factors in stem and progenitor cell mediated cardiac repair and tissue fibrosis. Fibrogenesis Tissue Repair. 2008;13(1):4. 13, 1.

4. Zhao C. Paracrine signaling in stem cell renewal and in neoplastic tumor growth. Sc China Life Sci. 2014;57:571-4.

5. Immune cells interact in surprising ways when responding to skin injuries (2015, June 10) retrieved 16 June 2015 from http:// medicalxpress.com/news/2015-06-immune-cells-interact-waysskin.html.

6. Gnecchi M, He H, Noiseux N, Liang OD, Zhang L, Morello F, et al. Evidence supporting paracrine hypothesis for Akt-modified mesenchymal stem cell-mediated cardiac protection and functional improvement. FASEB J. 2006;20(6):661-9.

7. Sigal SH, Brill S, Fiorino AS, Reid LM. The liver as a stem cell and lineage system. Am J Physiol Gastrointest Liver Physiol. 1992;2: G139-8.

8. Turner R, Lozoya O, Wang Y, Cardinale V, Gaudio E, Alpini G, et al. Human hepatic stem cell and maturational liver lineage biology. Hepatology. 2011;53:1035-5.

9. Beltrami AP, Barlucchi L, Torella D, Baker M, Limana F, Chimenti $\mathrm{S}$, et al. Adult cardiac stem cells are multipotent and support myocardial regeneration. Cell. 2003;114:763-6.

10. Barile L, Messina E, Giacomello A, Marbán E. Endogenous cardiac stem cells. Prog Cardiovasc Dis. 2007;50:31-8.

11. Seale P, Asakura A, Rudnicki MA. The potential of muscle stem cells. Dev Cell. 2001;1:333-2.

12. Goldring K, Partridge T, Watt D. Muscle stem cells. J Pathol. 2002;197:457-7.

13. Civin CI, Strauss LC, Brovall C, Fackler MJ, Schwartz JF, Shaper JH. Antigenic analysis of hematopoiesis. III. A hematopoietic progenitor cell surface antigen defined by a monoclonal antibody raised against KG-1a cells. J Immunol. 1984;133:157-5.

14. Orkin SH, Zon LI. Hematopoiesis: an evolving paradigm for stem cell biology. Cell. 2008;132:631-4.

15. Gunsilius E, Gastl G, Petzer AI. Hematopoietic stem cells. Biomed Pharmacother. 2001;55:186-4.

16. Forsberg EC, Bhattacharya D, Weissman IL. Hematopoietic stem cells: expression profiling and beyond. Stem Cell Rev. 2006;2:23.

17. Brandt SJ, Peters WP, Atwater SK, Kurtzberg J, Borowitz MJ, Jones RB, et al. Effect of recombinant human granulocytemacrophage colony-stimulating factor on hematopoietic reconstitution after high-dose chemotherapy and autologous bone marrow transplantation. N Engl J Med. 1988;318:869-6.

18. McNiece IK, Langley KE, Zsebo KM. Recombinant human stem cell factor synergizes with GM-CSF, G-CSF, IL-3 and epo to 
stimulate human progenitor cells of the myeloid and erythroid lineages. Exp Hematol. 1991;19:226-1.

19. Koury MJ, Bondurant MC. The mechanism of erythropoietin action. Am J Kidney Dis. 1991;18:20-3.

20. Mikkola HKA, Orkin SH. The journey of developing hematopoietic stem cells. Development. 2006;133:3733-4.

21. Bowman TV, Zon LI. Lessons from the niche for generation and expansion of hematopoietic stem cells. Drug Discov Today Ther Strateg. 2009;6(4):135.

22. Kaplan RN, Psaila B, Lyden D. Niche-to-niche migration of bonemarrow-derived cells. Trends Mol Med. 2007;13(2):72-1.

23. He N, Zhang L, Cui J, Li Z. Bone marrow vascular niche: home for hematopoietic stem cells. Bone marrow vascular niche: home for hematopoietic stem cells. Bone Marrow Res. 2014;2014(128436):8.

24. Lapidot T, Dar A, Kollet O. How do stem cells find their way home? Blood. 2005;106(6):1901.

25. Eichner ER. Blood doping: infusions, erythropoietin and artificial blood. Sports Med. 2007;37:389-1.

26. Dick JE, Magil MC, Huszar D, Phillips RA, Bernstein A. Introduction of a selectable gene into primitive stem cells capable of long-term reconstruction of the hemopoietic system of $\mathrm{W} / \mathrm{W}^{\mathrm{v}}$ mice. Cell. 1985;42:71-9.

27. Miller RH. The promise of stem cells for neural repair. Brain Res. 2003;1091:258-4.

28. Lu P, Jones LL, Snyder EY, Tuszynski MH. Neural stem cells constitutively secrete neurotrophic factors and promote extensive host axonal growth after spinal cord injury. Exp Neurol. 2003;181: 115-9.

29. Riquelme PA, Drapeau E, Doetsch F. Brain micro-ecologies: neural stem cell niches in the adult mammalian brain. Phil Trans R Soc B. 2008;363:123-7.

30. Fuentealba LC, Obernier K, Alvarez-Buylla A. Adult neural stem cells bridge their niche. Cell Stem Cell. 2012;10(6):698-8.

31. Shin Y, Yang K, Han S, Park H-J, Heo YS, Cho S-W. Reconstituting vascular microenvironment of neural stem cell niche in three-dimensional extracellular matrix. Adv Healthcare Mater. 2014;3:1457-4.

32. Bai L, Caplan A, Lennon D, Miller RH. Human mesenchymal stem cells signals regulate neural stem cell fate. Neurochem Res. 2007;32:353-2.

33. Aboody KS, Brown A, Rainov NG, Bower KA, Liu S, Yang W, et al. Neural stem cells display extensive tropism for pathology in adult brain: evidence from intracranial gliomas. PNAS. 2000;97: 12846-1.

34. Owen M, Friedenstein AJ. Stromal stem cells: marrow-derived osteogenic precursors. Ciba Found Symp. 1988;136:42.

35. Caplan AI, Haynesworth SE. Human mesenchymal stem cells. Patent No. 5,486,359. 1996. http://www.osiristx.com/

36. Caplan AI. Mesenchymal stem cells. J Ortho Res. 1991;9:641.

37. Caplan AI. The mesengenic process. Clin Plast Surg. 1994;21:429_ 5 .

38. Chan CK, Seo EY, Chen JY, Lo D, McArdle A, Sinha R, et al. Identification and specification of the mouse skeletal stem cell. Cell. 2015;160:285-8.

39. Mosca JD, McIntosh KR. Mesenchymal stem cells as immunosuppressants. 1999. US Patent No. 6797269B2.

40. Aggarwal S, Pittenger MF. Human mesenchymal stem cells modulate allogeneic immune cell responses. Blood. 2005;105:1185-2.

41. Rasmusson I. Immune modulation by mesenchymal stem cells. Exp Cell Res. 2006;312:2169-9.

42. Caplan AI, Bruder SP. Mesenchymal stem cells: building blocks for molecular medicine in the $21^{\text {st }}$ century. Trends Mol Med. 2001;6: 259-4.

43. Ankrum JA, Ong JF, Karp JM. Mesenchymal stem cells: immune evasive, not immune privileged. Nat Biotechnol. 2014;32:252.
44. Rosenberg ME. Cell-based therapies in kidney disease. Kidney Int Suppl. 2013;3:364-7.

45. Le Blanc K, Samuelsson H, Gustafsson B, Remberger M, Sundberg B, Arvidson J, et al. Transplantation of mesenchymal stem cells to enhance engraftment of hematopoietic stem cells. Leukemia. 2007;21:1733-8.

46. McKay R. Stem cells in the central nervous system. Science. 1997;276:66-1.

47. Bai L, Lennon DP, Eaton V, Maier K, Caplan AI, Miller SD, et al. Human bone marrow-derived mesenchymal stem cells induce Th2polarized immune response and promote endogenous repair in animal models of multiple sclerosis. Glia. 2009;57:1192-3.

48. Caplan AI, Dennis JE. Mesenchymal stem cells as trophic mediators. J Cell Biochem. 2006;98:1076-4.

49. Leventhal C, Farii S, Rafii D, Shahar A, Goldman SA. Endothelial trophic support of neuronal production and recruitment from the adult mammalian subependyma. Mol Cell Neurosci. 1999;13: $450-4$.

50. Zisa D, Shabbir A, Suzuki G, Lee T. Vascular endothelial growth factor (VEGF) as a key therapeutic trophic factor in bone marrow mesenchymal stem cell-mediated cardiac repair. Biochem Biophys Res Commun. 2009;390:834-8.

51. Wagers AJ, Weissman IL. Plasticity of adult stem cells. Cell. 2004;116:639-8.

52. Crisan M, Yap S, Casteilla L, Chen CW, Corselli M, Park TS, et al. A perivascular origin for mesenchymal stem cells in multiple human organs. Cell Stem Cell. 2008;3:301-3.

53. Caplan AI. All MSCs are pericytes? Cell Stem Cell. 2008;3:229.

54. Murphy MB, Moncivais K, Caplan AI. Mesenchymal stem cells: environmentally responsive therapeutics for regenerative medicine. Exp Mol Med. 2013;45, e54.

55. Caplan AI. What's in a name? Tiss Eng, Part A . 2010;16:2415-7.

56. Dennis JE, Charbord P. Origin and differentiation of human and murine stroma. Stem Cells. 2002;20:205-4.

57. Caplan AI, Dennis JE. Mesenchymal stem cells: progenitors, progeny and pathways. J Bone Min Metab. 1996;14:193-1.

58. Giuliani M, Oudrhiri N, Norman ZM, Vernochet A, Chouaib S, Azzarone B, et al. Human mesenchymal stem cells derived from induced pluripotent stem cells down-regulate $\mathrm{KN}$-cell cytolytic machinery. Blood. 2011;118(12):3254-4.

59. Villa-Diaz LG, Brown SE, Liu Y, Ross AM, Lahann J, Parent JM, et al. Derivation of mesenchymal stem cells from human induced pluripotent stem cells cultured on synthetic substrates. Stem Cells. 2012;30:1174-1.

60. Akashi K, He X, Chen J, Iwasaki H, Niu C, Steenhard B, et al. Transcriptional accessibility for genes of multiple tissues and hematopoietic lineages is hierarchically controlled during early hematopoiesis. Blood. 2003;101:383-9.

61. Merkle FT, Alvarez-Buylla A. Neural stem cells in mammalian development. Curr Opin Cell Biol. 2006;18:704-9.

62. Lymperi S, Ferraro F, Scadden DT. The HSC niche concept has turned 31: has our knowledge matured? Ann NY Acad Sci. 2010;1192:12-8.

63. Wurmser AE, Palmer TD, Gage FH. Cellular interactions in the stem cell niche. Science. 2004;304:1253-5.

64. Lindvall O, Kokaia Z. Stem cells for the treatment of neurological disorders. Nature. 2006;441:1094-6.

65. Snippert HJ, van der Flie LG, Sato T, van Es JH, van den Born M, Kroon-Veenboer $\mathrm{C}$, et al. Intestinal crypt homeostasis results from neutral competition between symmetrically dividing Lgr5 stem cells. Cell. 2010;143:134-4.

66. da Silva ML, Caplan AI, Nardi NB. In search of the in vivo identity of mesenchymal stem cells. Stem Cells. 2008;26:2287-9.

67. Imitola J, Park KI, Teng YD, Nisim S, Lachyankar M, Ourednik J, et al. Stem cells: cross-talk and developmental programs. Phil Trans R Soc Lond. 2004;359:823-7. 
68. Baraniak PR, McDevitt TC. Stem cell paracrine actions and tissue regeneration. Regen Med. 2010;5:121-3.

69. Clerici M, Cassinotti A, Onida F, Trabattoni D, Analoro C, Volpe $\mathrm{AD}$, et al. Immunomodulatory effects of unselected haematopoietic stem cells autotransplantation in refractory Crohn's disease. Dig Liver Dis. 2011;43:946-2.

70. Lee ST, Chu K, Jung KH, Kim SJ, Kim DH, Kang KM, et al. Antiinflammatory mechanism of intravascular neural stem cell transplantation in haemorrhagic stroke. Brain. 2008;131:616-9.

71. Galipeau J, Krampera M. The challenge of defining mesenchymal stromal cell potency assays and their potential use of release criteria. Cytotherapy. 2015;17:125-7.

72. Haynesworth SE, Baber MA, Caplan AI. Cytokine expression by human marrow-derived mesenchymal progenitor cells in vitro: effects of dexamethasone and IL-1 $\alpha$. J Cell Physiol. 1996;166:585-2.

73. Liu S, Jiang L, Li H, Shi H, Luo H, Zhang Y, et al. Mesenchymal stem cells prevent hypertrophic scar formation via inflammatory regulation when undergoing apoptosis. J Invest Dermatol. 2014; 134:2648-7.

74. Liu YL, Liu YW, Sun J, Hou TJ, Liu YM, Liu HR, et al. Mesenchymal stem cell-mediated suppression of hypertrophic scarring is p53 dependent in a rabbit ear model. Stem Cell Res Ther. 2014;5:136.
75. Ting AE, Mays RW, Frey MR, Van't Hof W, Medicetty S, Deans R. Therapeutic pathways of adult stem cell repair. Crit Rev Oncol Hematol. 2008;65:81-3.

76. Shehadah A, Chen J, Pal A, He S, Zeitlin A, Cui X, et al. Human placenta-derived adherent cell treatment of experimental stroke promotes functional recovery after stroke in young adult and older rats. PLoS One. 2014;9, e86621.

77. Penn MS. Stem cell effects at a distance. Circ Res. 2012;111:12-2.

78. Karp JM, Teo GSL. Mesenchymal stem cell homing: the devil is in the details. Cell Stem Cell. 2009;4:206-6.

79. Agrawal V, Johnson SA, Reing J, Zhang L, Tottey S, Wang $\mathrm{G}$, et al. Epimorphic regeneration approach to tissue replacement in adult mammals. Proc Natl Acad Sci. 2009;107: 3351-5.

80. Turner NJ, Keane TJ, Badylak SF. Lessons from developmental biology for regenerative medicine. Birth Defects Res C Embryo Today. 2013;99:149-9.

81. Feldman JL, Stockdale FE. Skeletal muscle satellite cell diversity: satellite cells form fibers of different types in cell culture. Dev Biol. 1991;143:320-4.

82. Schmalbruch H. Satellite cell of skeletal muscle fibres. Braz J Morphol Sci. 2006;23:159-2. 